\title{
Awareness, Partisanship and the Post-Convention Bounce: A Memory-Based Model of Post- Convention Presidential Candidate Evaluations Part 1-Introduction \& Theoretical Analysis
}

\author{
Justin Grimmer \\ Department of Mathematics and Computer Science \\ Wabash College \\ Crawfordsville, Indiana 47933 USA
}

Received: June 6, 2004

Accepted: September 24, 2004

\begin{abstract}
This paper employs panel data to estimate the effects of awareness and political partisanship on post-convention candidate evaluations. The theoretical framework proposed by John Zaller (1992) is employed; however, a functional form that differs greatly from Zaller's proposed model is derived from Zaller's assumption and then estimated using standard OLS regression. I find that partisans of the opposite party were more resistant to the convention message of Bush than Gore, awareness plays a greater role in determining predicted post-convention change for Gore, and that Gore's message was received and accepted at a higher rate than Bush's message.
\end{abstract}

\section{INTRODUCTION}

The Republican and Democratic nominating conventions comprise two of the most important events of the campaign season in the US, with media attention coalescing around the candidate and his party for a week. The 2000 conventions were no different, with an immense amount of focus placed on both candidates while in convention. Normally, aggregate measures of opinion regarding candidate evaluations and intended vote are reported by every major network and used as a measure of how the public is responding to a candidate's message during a convention. Convention induced opinion change does not, however, occur on the macro level. Opinion change is a personal or micro phenomenon that depends upon respondents' characteristics. Therefore a model based upon and estimated with individual respondents is necessary to assess the effect of a convention on respondents' evaluations of candidates.

In order to model micro level opinion change regarding candidate evaluation after the nomination convention we employ Zaller's memory-based model of opinion change [1]. This allows an examination of how awareness and partisanship affect the internalization of the convention messages. First, we review Zaller's and a competing model of opinion change, and review literature about public opinion and media dynamics surrounding nominating conventions. Then, the four central axioms of Zaller's theory are employed to derive a functional form for analysis. We estimate this functional form for four models, and analyze the patterns of opinion change after conventions. Our conclusions are that partisanship resistance was stronger to the message of Bush, the awareness of respondents played a more crucial role in determining opinion change for Gore, and finally that Gore's post-convention predicted feeling thermometer was higher than Bush's predicted feeling thermometer for most respondents.

I. Literature Review

a. Reception-Acceptance Model

Zaller attempts to decipher the dynamics of public opinion using a memorybased approach, which he calls the 
"reception-acceptance model" [1]. He bases his reception-acceptance model on the premise that individuals do not have determined opinions on political issues. Rather, personal and environmental factors interact to determine the individual's opinion. His model is not, however, the only one that might be used to explain how conventions might shape opinion during the US presidential campaign. In this section, we will elaborate Zaller's model, analyze how Zaller places this model in the context of elections, summarize an alternative model, and then summarize research regarding nominating conventions to illustrate how Zaller's model can be applied to this process [1].

The reception-acceptance model is based upon four central axioms, or assumptions, that attempt to approximate the method by which individuals evaluate new information. These axioms define how new information interacts with considerations, which Zaller defines as, "any reason that might induce an individual to decide a political issue one way or the other" [1]. The four axioms are restated below:

Axiom 1: Individuals with a high level of cognitive engagement will have high probabilities of both observing and understanding a political message.

Axiom 2: Individuals tend to resist arguments that run against their political predispositions, provided that they possess information that links the message and their predisposition.

Axiom 3: The more recent a consideration has been called to mind the more likely the respondent will employ that consideration in her response to a survey question.

Axiom 4: Individuals respond to survey questions by averaging across the salient considerations.

From these axioms, Zaller develops a statistical model that estimates the probability that an individual will change her opinion on a given issue [1]. Equation 1 governs opinion change within the reception-acceptance framework:

$$
\begin{aligned}
& P(\text { Change })= \\
& P(\text { Reception }) \cdot P(\text { Acceptance } \mid \text { Reception })
\end{aligned}
$$

That is, the probability that an individual will change her opinion is equal to the product of the probability that a message has been received and the probability that a message is accepted given that it has been received. Zaller defines the reception function as a monotonically increasing function of awareness, while the acceptance given reception function is a monotonically decreasing function of ideological distance from the message and awareness. The two key variables in the reception-acceptance dynamic are political awareness and partisan/ideological position [1].

Zaller identifies the dynamics of opinion change in congressional elections as governed by the reception-acceptance model. He asserts that a respondent's level of political awareness and her ideological position govern an individual's probability of defecting towards an incumbent of the opposing party. In order to test this hypothesis, Zaller analyzes individuals who defect in a congressional race and vote for an incumbent of the opposing party. In order to identify the probability that an individual defects, as estimated by Zaller [1], is given in Equation 2.

The functional form for both the reception and acceptance models is logistic. These models are suitable for probabilities because they are bounded by 0 and 1 . Further, the reception-acceptance model asserts that those with mid-range awareness and partisanship strength should be most likely to change opinion, which the logistic functional form captures. See Zaller [1], pages 133-137, for examples of the logistic functional form.

$$
P(\text { Defection })=1-\left(1+\operatorname{EXP}\left[\alpha_{0}+\alpha_{1} \cdot \text { Awareness }+\alpha \cdot \mathbf{x}\right]\right)^{-1} \times\left(1+\operatorname{EXP}\left[-\beta_{0}-\beta_{1} \cdot \text { Awareness }\right]-\beta \cdot \mathbf{y}\right)^{-1}
$$

where $\alpha_{0}$ and $\beta_{0}$ describe the intercept for the reception and acceptance functions, $\alpha_{1}$ and $\beta_{1}$ describe the coefficient on awareness in the reception and awareness functions $\alpha$ 


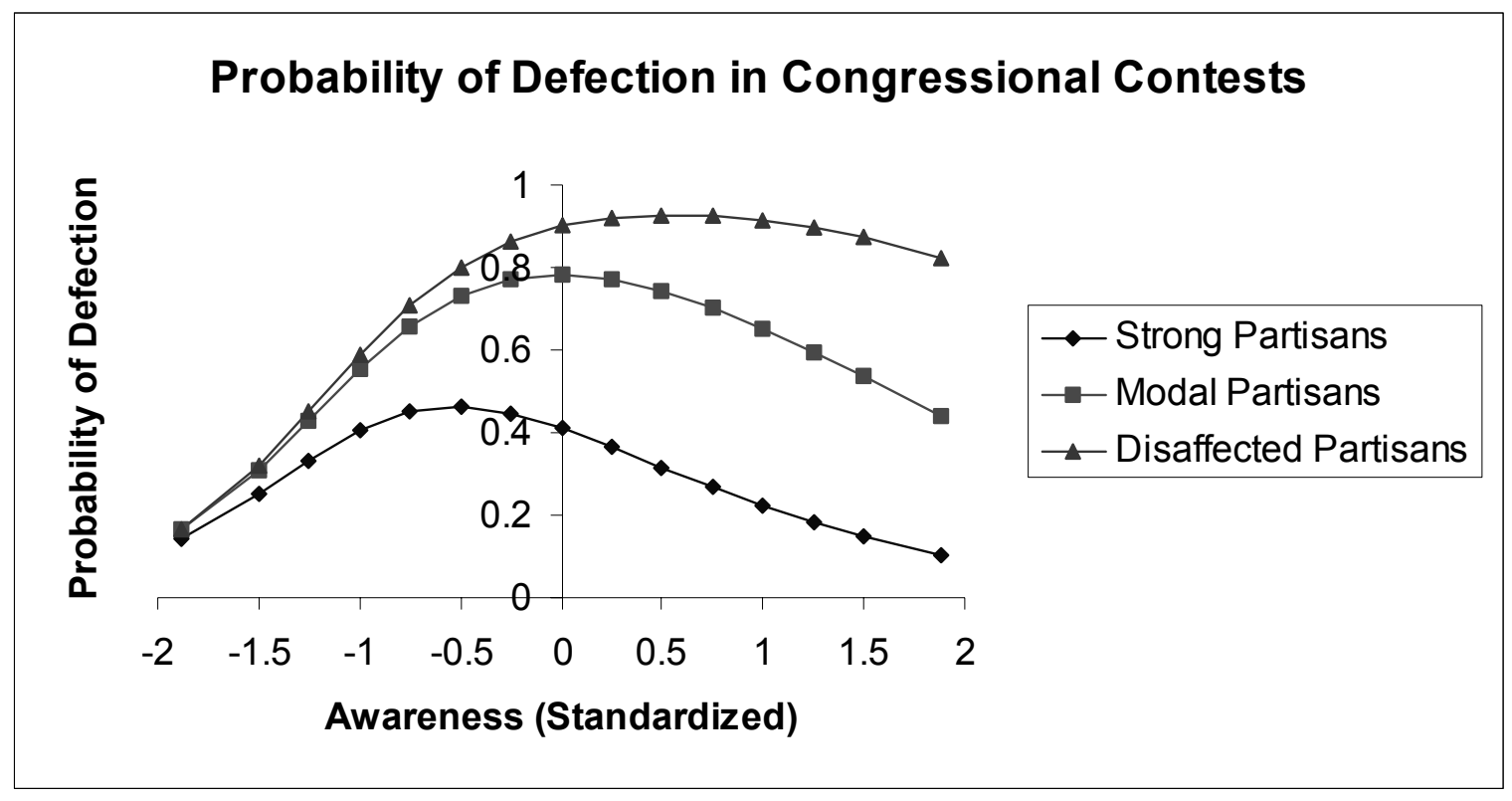

Graph 1. Probability of Defection in Congressional Elections.

and $\beta$ correspond to parameter vectors and $\mathbf{x}$ and $\mathbf{y}$ correspond to vectors of independent variables in the reception function and acceptance functions respectively. Equation 2 was estimated using maximum likelihood methods $[1,2]$.

Due to the interaction of terms in Equation 2, graphical analysis is needed in order to decipher Zaller's results [1]. Figure 1 simulates the probability for defection among three different partisan types, as awareness varies. Parameter estimates were obtained from Table 10.1, (Zaller [1] $p$ 222). The strong partisan was simulated with a Party strength of 2.7 and a Partisan inertia of 3 , while the modal partisan was estimated with a Party strength of 1.3 and a partisan inertia score of 0.7 . Finally, the disaffected partisan was simulated with a 0 on party strength and a -3.0 on partisan inertia.

As Graph 1 shows, the probability of defection is non-monotonic in nature; the highest probability for defection among each partisan type occurs among respondents with a mid-level of awareness. Strong partisans are less likely to defect than weak partisans. The stronger one's partisanship and the higher one's awareness, the less likely the individual is to switch parties. Therefore, awareness and partisanship act as inertial forces against opinion change.

\section{b. On-Line Model}

In 1995, Lodge, Steenbergen, and Brau proposed a model where individuals update their evaluations of political candidates as new information is observed, the "on-line" model [3]. They assert that their theoretical framework corrects for forgotten considerations and offers an alternative to normative complaints about the American public's lack of knowledge about candidates and issues.

Figure 1 shows a recreation of the figure that the authors use to represent the dynamics of the on-line model [3]. First, when individuals want to make a judgment about a political candidate they will make an evaluation of new knowledge immediately, and then add this new information to a tally, which is a store of evaluations before the new information was observed. This updated tally is added to the long-term memory and the considerations surrounding the updated tally are quickly forgotten. An example of how information is processed and flows through Figure 1 will be helpful. Assume that a new piece of information is received, such as a scandal regarding presidential candidate $X$. This new information is then added to the on-line tally, where the previous evaluation of the candidate is altered, dropping the opinion of 


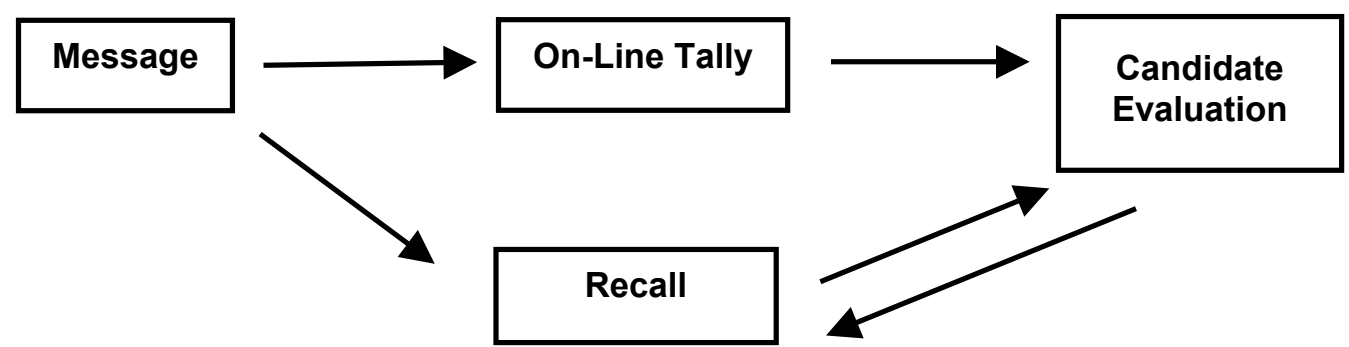

Figure 1. The On-Line Model.

the candidate from a favorable to an unfavorable level. Now, moving right in the figure, the on-line tally is added to the longterm memory as a candidate evaluation. Then, when asked to recall, the respondent will be able to remember the new on-line tally, but will be unable to remember the exact message that had been received (thus the broken arrow heading from recall to candidate evaluation).

Zaller has argued that the on-line model of information processing may be inappropriate. $\mathrm{He}$ notes that political information may be so unimportant to individuals that they may not keep a running tally of their evaluations of candidates $[1, p p$ 32-33].

\section{c. Model Comparisons}

The on-line model offers, however, a secondary interpretation of the Zaller analysis, and it is possible that presidential campaigns command a large enough share of the public's attention that the on-line model may be appropriate.

The application of the Zaller reception-acceptance model within the framework of nominating conventions requires an understanding of conventions' effects on public opinion and how the media alter campaign coverage surrounding conventions. In order to investigate the sustained effect of nominating conventions from 1952-1992 on public opinion, Shaw [4] employs time-series analysis (GLS). Shaw identifies nominating conventions as one of the most important events in the campaign season. He argues that news media coverage coalesces around the conventions and all major networks cover the convention for four nights. With such broad coverage, the public has a high probability of obtaining knowledge about the convention.
To estimate the effects of conventions on the percentage of the public that intends to vote for a given candidate Shaw estimates a time-series model of aggregate intended voting. This model allows him to identify a parameter that estimates the immediate effect that a campaign event has on the percentage of the public voting for a given candidate and a second parameter that estimates decay of the message's impact. Shaw's findings indicate that conventions are in fact the most important campaign event of the presidential race. First, the immediate impact of the convention is large. Secondly, Shaw finds that conventions have a sustained effect on percent of the public voting for a candidate. $\mathrm{He}$ identifies the dynamics of public opinion as a "step effect" or a campaign event that has a large immediate effect on public opinion that is sustained as the campaign continues. Therefore, Shaw demonstrates that at the aggregate level nominating conventions alter public opinion over the course of elections [4].

Joslyn and Ceccoli [5] have investigated television news coverage of the 1992 election, an aspect that is of crucial importance to the reception-acceptance model, as opinion change is dependent upon the information stream from the media. They assert that the media play an important role in determining the stream of information that individuals receive during the presidential campaign. Their analysis focuses on the nightly news broadcasts of $A B C, C B S$ and NBC because of their centrality within the American information delivery system.

Joslyn and Ceccoli focus upon two major aspects of news coverage: the percentage of news stories about a candidate during a given week of the 
campaign and the positive or negative nature of the campaign coverage. First, the authors find that, on the whole, the percentage of stories about a given candidate is approximately $50 \%$, evidence that the amount of coverage is balanced. In addition, the authors find that coverage for a candidate peaks when the candidate's party holds its nominating convention. Both George H.W. Bush and Clinton obtained their highest level of coverage at their conventions, both receiving about $75 \%$ of the media coverage. Therefore, the information stream to voters becomes more one-dimensional around conventions.

The Joslyn and Ceccoli [5] also estimate the negative-positive balance in the media coverage of the 1992 election. They define their estimate of appraisal as the sum of positive news statements minus the sum of all negative news statements regarding presidential candidates. Joslyn and Ceccoli find that the coverage of Clinton was predominantly positive throughout the campaign and was only more negative than the Bush campaign for the week of August 23, 1992. The Bush campaign experienced much more negative evaluations throughout the campaign, receiving more negative than positive statements for every week in the analysis. Thus, Joslyn and Ceccoli determine that the media coverage of a presidential election coalesces around the candidate in convention and that the media may treat one campaign as more negative than others.

Nominating conventions have a large impact on aggregate levels of reported voting intention and they appear to impact the media coverage of the presidential election. In order to determine how the nominating convention and the associated focusing of media coverage affects individuals' evaluations of political candidates, we will apply the Zaller reception-acceptance model to a nondichotomous dependent variable, postconvention feeling thermometer. The next section develops my theoretical argument and describes the reception-acceptance model of the 2000 nominating conventions.

\section{THEORETICAL ANALYSIS}

As our literature review showed, the nominating convention plays a role in both the aggregate measures of intended voting and the information stream that the media provides the public. We first offer a simplifying assumption regarding information streams of nominating conventions and subject this assumption to an empirical test. We then deduce the functional form of our model predicting post-convention feeling thermometers, based on the four axioms of the reception-acceptance model.

In order to simplify the functional form of our model, let us assume that there is only one message surrounding conventions, the message of the party that is in convention. Joslyn and Ceccoli [5] have showed that the coverage of the presidential campaign on network news in 1992 election shifted towards the candidate who was in convention. In order to verify that a similar dynamic occurred in the 2000 presidential election, we have analyzed Time Magazine, US News and World Report, and Newsweek from June $26^{\text {th }}$ to September 11, 2000 in order to determine the percentage of Bush or Gore stories that were dedicated to one specific candidate. The magazines were selected based upon their position of prominence and large readerships. A story was defined solely a Bush or Gore article when the primary focus of the article was centered upon ideological position or campaign dynamics of one campaign, without comparisons to the opposing candidate. Articles were defined as Bush/Gore if the article compared the stances of the two candidates or dealt with the horse race aspect of the election and were scored as an article for both Bush and Gore.

Graph 2 displays the results of the review. First, note that in the five weeks prior to the convention the media coverage was fairly balanced. However, during the week of the Republican convention the percentage of Bush stories obtains its maximum value of $87.5 \%$. Further, there is a lag in media coverage of conventions, with Bush as the topic of $80 \%$ of the stories in the week after the convention. Coverage around the Democratic convention manifests a similar pattern. Only $13.33 \%$ of stories contain Bush as a subject during the week of the Democratic convention. Thus, while the messages are not purely one message surrounding a convention, there is a significant shift in the media coverage and 


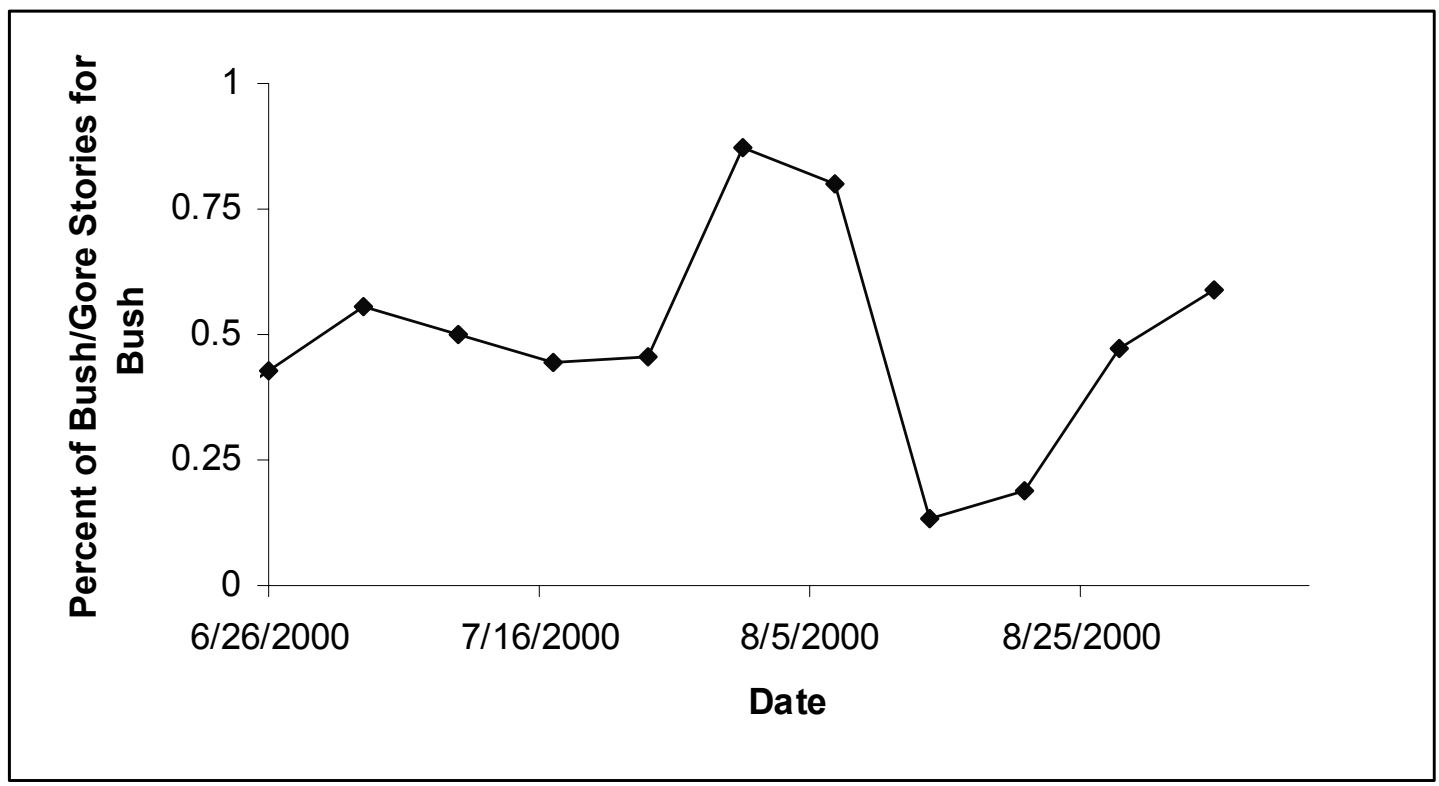

Graph 2. Percentages of Bush/Gore Stories for Bush.

the one-message appears to be an appropriate simplification and provides an acceptable starting point for analysis [6]. This analysis stops short of any normative assessment of problems with media coverage in the 2000 election. Lichther and Patterson [7] offer critiques of problematic aspects of media coverage, including depiction of campaigns as races and the possibility of media bias.

Given the one-message information stream and following Zaller's deductions throughout his book, we derive the functional form for our analysis. First, we note that individuals who are more aware are more likely to receive information regarding an election (Axiom 1). Conversely individuals with a high level of awareness are less likely to accept messages (Axiom 2). Further, strong partisans will have predispositions that will cause them to resist messages of the opposing party (Axiom 3). Zaller asserts that interaction between measures of partisanship and ideological orientation and awareness is necessary, because the resistance that occurs due to partisanship occurs only when the proper contextual information is available (Axiom 2) ([1] p 137).
Because we are dealing with specific candidate evaluations and lack open-ended response questions, we will use the pre-convention feeling thermometer for each candidate as a measure of respondent considerations regarding the candidate before the convention. Because the campaigns for both candidates had been underway for quite some time before the conventions, it is likely that respondents had assimilated considerations regarding both candidates. These old considerations could be made salient via the convention and could then play a role in determining the post-convention feeling thermometer (Axiom 4). This argument differs in a key regard to the on-line model. The on-line model would suggest that the convention provides new information from which the respondent updates a running tally of the candidate. In a similar fashion, information regarding amount of time spent watching the GOP convention is included for respondents in the Democratic convention sample, because the considerations assimilated during the GOP convention may be salient for the Democratic convention (Axiom 4).

Eqn. 3 is the functional form that we will use to determine the effect of nominating conventions on candidate evaluations:

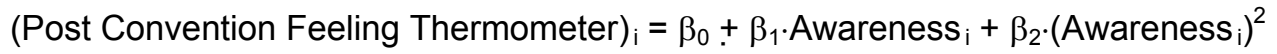

$$
\left.+\beta_{3} \text {.Awareness.(Partisanship }+ \text { Ideological Distance }\right)_{i}+\alpha x_{i}+\varepsilon_{i}
$$




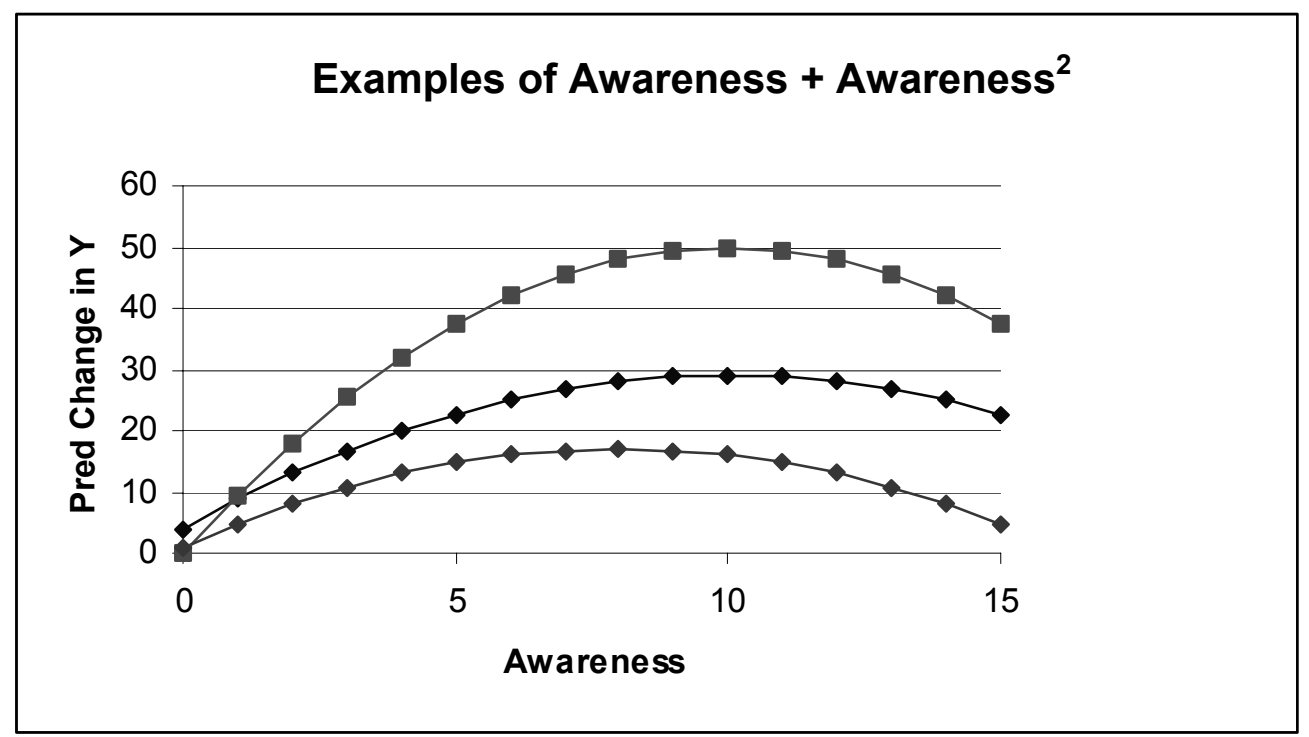

Graph 3. The examples shown above were constructed using the equation (Predicted Change in $\mathrm{Y})=$ Intercept $+\mathrm{b} 1$-awareness $+\mathrm{b} 2 \cdot(\text { awareness })^{2}$. Awareness runs on a 0-15 scale, the intercept, b1 and b2 values of each curve are as follows: Top $\{0.10,-0.5\}$, Middle $\{4,5,-0.25\}$, Bottom $\{1$, $4,-0.25\}$.

where the $\beta$ 's are parameter estimates, awareness and partisanship are index values (derived below), $\alpha$ is a vector of parameter estimates, $\mathbf{x}$ is a vector of independent variables that includes the preconvention feeling thermometer and information regarding self-reported viewing of the conventions, and the $\varepsilon$. term represents a normally distributed error term, all for the $i^{\text {th }}$ respondent in the survey. (See the Appendix for details of the Awareness and Partisan Indices.)

Equation 3, while it deviates from the functional form of Zaller's model, will still allow the capture of the receptionacceptance dynamic. First, the inclusion of the (awareness) ${ }^{2}$ term allows for the increased resistance associated with higher levels of awareness. In order to understand how (awareness) ${ }^{2}$ captures the inertial resistance to incoming information associated with higher levels of awareness, consider a brief example. Graph 3 plots three different functions of the intercept, awareness, and (awareness) ${ }^{2}$ parameters. As awareness initially increases, there is a larger change in the predicted dependent variable (which, in our study, will be the feeling thermometer). However, for each function we see that a maximum roughly occurs at the middle level of awareness, and the predicted change in the dependent variable is diminished as awareness reaches its maximum value of fifteen.

We have been able to capture, in a similar fashion, interactions between awareness, and political partisanship and ideological leaning. Graph 4 shows three different levels of partisanship associated with the same function described in Graph 3. Those of the same partisan orientation as the message have a higher predicted change in the dependent variable than independents or strong opposing partisans. Thus, we are able to account for the conclusion reached from Axioms 2 and 3 , that contextual information will play a role in formation of opinion.

Estimation of Equation 3 will allow an explicit test of the extent to which awareness and political predispositions act as resistance mechanisms to the onemessage format of the nomination conventions. Therefore, we hypothesize that respondents who are not of the same political leaning as the party in convention will resist the message of the convention more strongly than those of the convention's partisanship. We further hypothesize that awareness will cause a non-monotonic reception of the convention message, resulting in those with a medium level of awareness altering their evaluations of the candidates the greatest. These hypotheses 


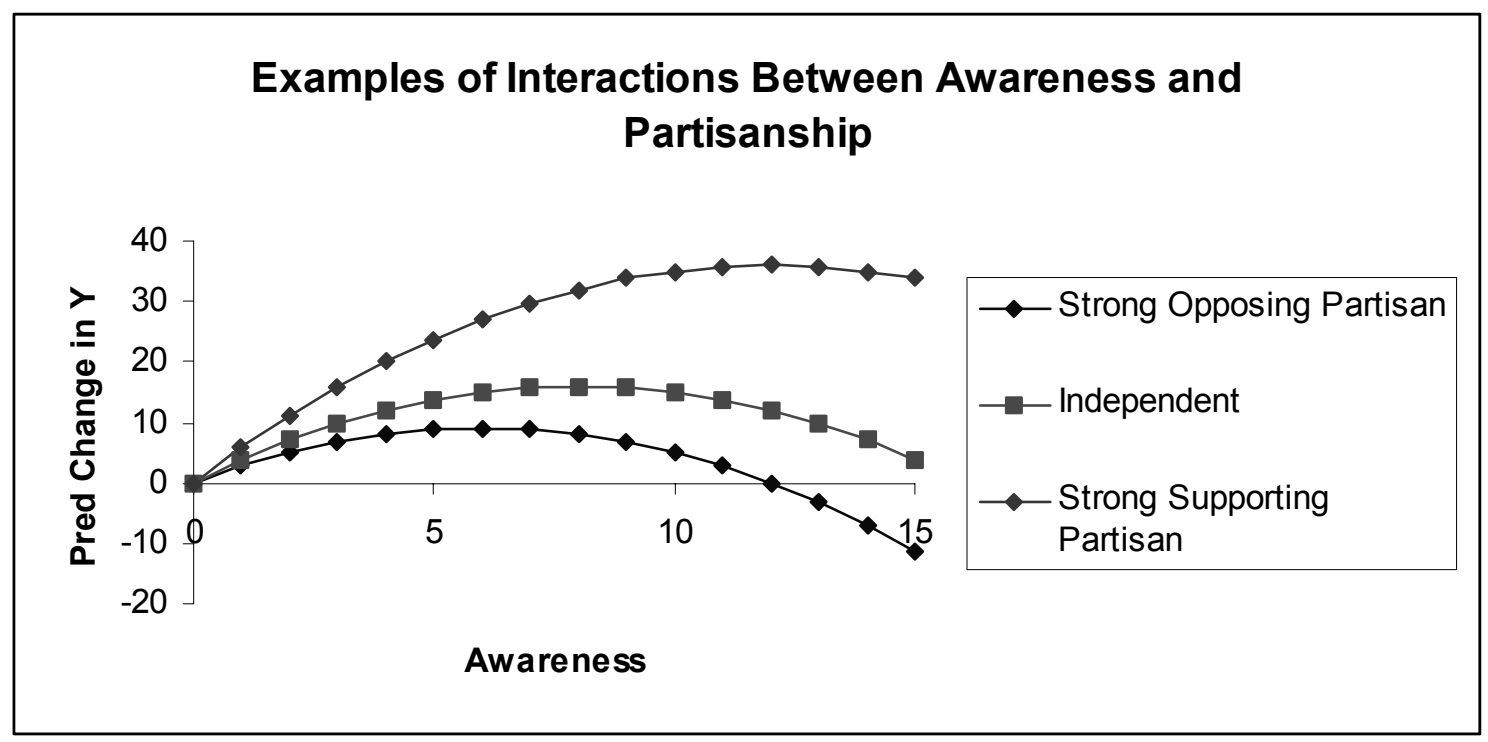

Graph 4. For all three functions shown above, the intercept was taken to be 0 , the slope on Awareness is 4 , the parameter on Awareness ${ }^{2}$ is -0.25 , and the parameter on the interaction term is 5. The level of partisanship for the strong supporting Partisan is 4 , the independent is 0 , and the strong opposing Partisan is -4 .

will allow a test of the model's ability to capture dynamics of opinion change during conventions, through significance tests. However, this will be made more difficult due to the presence of multicollinearity in my models. The index value awareness appears in three different forms in my equation, causing multicollinearity, which causes the standard errors to become much larger. Further discussion of this fact will be undertaken in part II of this research report, which will appear in the March 2005 issue of this journal.

\section{APPENDIX}

a. Items in the Awareness Index

Item 1) Interviewer Ranking of Individual's knowledge [A is highest ranking]:

$$
\begin{aligned}
& A=4 \quad B=3 \quad C=2 \quad D=1 \\
& \mathrm{~F}=0
\end{aligned}
$$

Item 2) Placement of George W Bush to the Right of Al Gore on ideological scale:

Bush identified as more conservative than Gore $=1$

Bush equal to or more liberal than Gore $=0$

Item 3) Correct ID of Bush as Governor:

ID Bush as Governor $=1$

Incorrect ID = 0
Item 4) Correct ID of Al Gore as former senator:

ID Gore as Former Senator $=1$

Incorrect $=0$

Item 5) Correct ID as George W Bush as the candidate that spoke at Bob Jones University:

ID Bush as Candidate $=1$

Incorrect $=0$

Item 6) Correct ID as Gore as son of former senator:

ID Gore as son of former senator $=1$

Incorrect $=0$

Item 7) Correct ID as Bush as "born again" Christian:

ID Bush as Christian = 1

Incorrect $=0$

Item 8) Correct ID of Bush as baseball team owner:

ID Bush as owner $=1$

Incorrect $=0$

Awareness Index $=$ Sum of Item Scores

b. Items in the Partisanship Index

Illustrated for the Republican convention, multiply the score by -1 to create the index for the Democratic convention.

Item 1) Partisan Identification:

$$
\text { Republican }=1 \text {; Democrat }=-1
$$


Item 2) Strong Party Identification:

Strong Republican $=1$, Democrat $=-1$ Item 3) Leaning toward Republicans or Democrats:

Toward Republicans $=1 / 2$

Toward Democrats $=-1 / 2$

Item 4) Self-evaluation on a liberalconservative scale:

Very Conservative $=2$

Conservative $=1$

Moderate $=0$

Liberal $=-1$

Very Liberal $=-2$

Partisanship Index = Sum of Item scores.

\section{REFERENCES}

1. Zaller, John R; The Nature and Origins of Mass Opinion (Cambridge University Press, Cambridge, UK, 1992).

2. Anton, Howard; Rorres, Chris; Elementary Linear Algebra 2000, John Wiley and Sons, New York.
3. Lodge, Milton; Steenbergen, Marco R; Brau, Shawn; "The Responsive Voter: Campaign Information and the Dynamics of Candidate Evaluation" The American Political Science Review 89, 2 (1995).

4. Shaw, Daron "A Study of Presidential Campaign Event Effects from 1952 to 1999" The Journal of Politics 61,2 1999 387-422.

5. Joslyn, Mark R; Ceccoli, Steve "Attentiveness to Television News and Opinion Change in the fall 1992 Presidential Campaign" Political Behavior 18, 21996 141-170

6. Patterson, Thomas E. The Vanishing Voter: Public Involvement in an Age of Uncertainty, 2003 Alfred Knopf, New York, pp 63-98.

7. Lichter, Robert S. "A Plague on Both Parties: Substance and Fairness in TV Election News" Harvard International Journal of Press/Politics 6 (2001), pp 830.

\section{University of Northern lowa Center for Energy and}

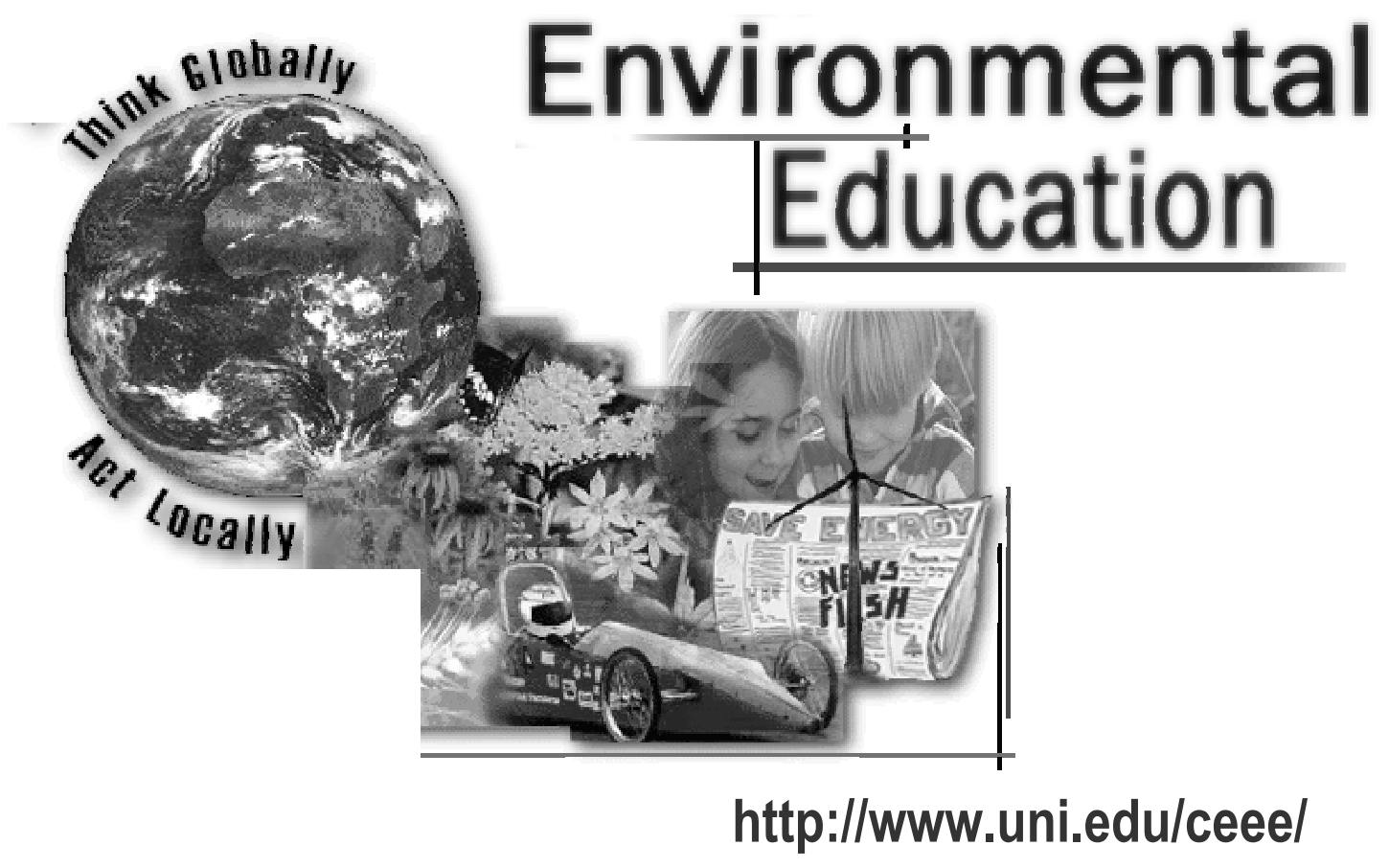


